\title{
School-Based Interventions to Enhance the Resilience of Students
}

\author{
Michael Ungar ${ }^{1}$, Patrick Russell ${ }^{2} \&$ Gerry Connelly ${ }^{3}$ \\ ${ }^{1}$ Dalhousie University, Resilience Research Centre, Halifax, Canada \\ ${ }^{2}$ Resilience Research Centre-Evaluation and Training Institute, Halifax, Canada \\ ${ }^{3}$ The Learning Partnership, Toronto, Canada \\ Correspondence: Michael Ungar, Resilience Research Centre, Dalhousie University. P.O. Box 15000, 6420 \\ Coburg Rd., Halifax, Nova Scotia, B3H4R2, Canada. Tel: 1-902-494-3050. E-mail: Michael.ungar@dal.ca
}

Received: October 26, 2013

Accepted: November 20, 2013

Online Published: March 12, 2014

doi:10.5539/jedp.v4n1p66

URL: http://dx.doi.org/10.5539/jedp.v4n1p66

\begin{abstract}
A scoping review of programs targeting middle school students suggests that resilience is seldom the result of interventions within schools alone, or any other single system that provides services to students. Instead, resilience is shown to be a multidimensional construct, involving both exposure to risk and access to multiple internal and external resources. Based on a scoping review of outcomes from 36 interventions, we highlight the elements of successful programs with vulnerable students and reasons for why some programs appear to be less effective or have a negative impact. Less successful programs tended to be those that did not include a cultural component or show sensitivity to contextual variations among students like the size of their community, access to other services and supports, or the economic status of the child's family. The biases of funders, researchers and educators also influence the choice of resilience-promoting intervention made available in a school rather than the specific needs of the targeted student population. We conclude with several recommendations for more effective interventions with students and the implications of our findings to the evaluation of program outcomes.
\end{abstract}

Keywords: resilience, students, adolescents, successful interventions, culture

\section{Introduction}

Students face a wide array of barriers in their lives that not only jeopardize their performance in, and completion of, school but also jeopardize their physical health and psychological wellbeing in ways that can follow them into their adult lives (Mallin, Walker, \& Levin, 2013). There is, fortunately, emerging evidence that schools have the potential to influence positively children's biopsychosocial growth and development though much more work needs to be done to identify which protective factors are most likely to be affected by school-based interventions, the role schools can play in collaboration with children's families, communities, and other service providers, and to what extent interventions need to focus on changing children's school environments rather than changing children themselves (France, Bottrell, \& Armstrong, 2012; Ungar \& Liebenberg, 2013).

\section{Method}

To investigate the potential for school-based interventions to protect and promote children's wellbeing, we conducted a purposeful search of the literature (a scoping review) using a number of search terms to sort published journal articles and books that had been indexed as well as identify nonacademic reports on programs that had been described online. Using the search capacity of WorldCat, we were able to conduct a simultaneous search of all major indices in the fields of Psychology, Sociology and Education. We also included searches of Google Scholar and Google to identify examples of programs that were not published in the formal literature (e.g., reports from government departments, school boards, and non-governmental organizations). Search terms included "resilience and schools", "school resilience" and "student resilience", among others. Articles, books, and reports were selected if they referred to a specific program or intervention that was intended to enhance the resilience of students while they attended school.

To narrow our focus and maintain some degree of homogeneity in our target population, we began by looking exclusively at reports on programs serving Canadian students ages 10-14. We found, however, that there was a limited number of interventions for this population and therefore expanded the scope of our search to include international program evaluations with students of different ages. Our intention was not to provide a 
comprehensive survey of the literature, but to search for exemplars of best practices and programs that had an evidence base. When our search results showed repetition in the types of programs identified, or outcomes were consistently positive or negative (or indeterminate), we proceeded with a search for exemplars of another type of intervention to see if the same pattern in the results could be identified. In this way, our results provide a thematic analysis of the literature rather than an empirical review. This thematic approach allowed us to observe trends among programs with emerging practice-based evidence, as well as those that have been more formally evaluated. We would expect that replication of this scoping review would produce a different list of programs from those detailed in Table 1, but that the dominant themes we have found among these 36 programs would continue as a trustworthy description of program elements that contribute to the resilience of students at school.

\section{Resilience in Schools}

Our review approached the problem of resilience from a social ecological perspective (Ungar, 2011) as it relates to education (Ungar \& Liebenberg, 2013). For decades, the concept of resilience has been providing a way of understanding children's positive development under adversity and the factors and processes that help children avoid harmful, self-destructive, or antisocial behaviours, mental disorders, and threats to their physical wellbeing (Richman \& Fraser, 2001). Understood in this way, resilience is the individual's participation in processes that make positive developmental outcomes possible. For children facing significant adversity, engagement in protective and promotive processes that enhance wellbeing can be influenced by the provision of formal interventions. Resilience is, therefore, not just the personal qualities of the child, but how well the child's social and physical environment (including the child's school, family, and community) facilitates access to internal and external resources such as healthy relationships, a powerful identity, social justice, material needs like food and education, and a sense of belonging, life purpose and spirituality (Ungar et al., 2007). A child who is given the help he or she needs to navigate to such resources and negotiate for them to be provided in meaningful ways (e.g., culturally relevant) is more likely to do well (Ungar, Liebenberg, Armstrong, Dudding, \& van de Vijver, 2012).

\section{Academic Achievement or School Engagement?}

To assess whether a school intervention bolsters resilience, the most common outcomes reported included academic achievement and school engagement. For children who attend school regularly and face less social disadvantage, academic achievement tends to be the more important predictor of resilience than school engagement. For example, studies by Martin and Marsh $(2008 ; 2009)$ have shown that students who do not score high on contextual risk factors (their homes and communities are reasonably well functioning and financially stable) still experience normative challenges related to being in school during tumultuous periods of psychological and social development. All students, they explain, suffer stress related to writing tests, forming and ending of romantic relationships with other students, and transitioning between grade levels. Resilience at school (in particular academic success) is best understood as the outcome of interactions between both common and exceptional risk factors, contextual risk factors beyond the school, a quality educational environment, and the child's individual strengths.

For students exposed to higher levels of individual, family, school and community stress, school engagement is the more important factor associated with resilience rather than academic achievement. A child who engages at school experiences a passageway (Hobfoll, 2011) to a host of potentially supportive experiences. In contrast, the less stressed child is more likely to have access to internal and external resources at home and at school, making school relatively less important. Therefore, a child who shows a positive attitude towards school, is optimistic that schooling can change life trajectories, and demonstrates engagement through attendance has been shown to be much more likely to have better overall wellbeing regardless of the child's academic achievement (Dotterer, McHale, \& Crouter, 2009).

For our purposes here, we examined educational programming (beyond the basic pedagogical practices in classrooms) that focused on improving children's mental and physical health, school engagement and academic achievement. Therefore, in addition to the school related outcomes of engagement and achievement, a program was seen as building resilience if it successfully addressed risks to a student's wellbeing and facilitated the student in processes that helped him or her build capacities for successful adaptation under stress. These capacities include: improvement in the size and quality of a child's relationships; the development of a more powerful and positive identity; experiences of efficacy and an internal locus of control; better and just treatment by others; improved access to material resources like quality food, clothing, shelter, and educational supports; social cohesion and a sense of belonging or spirituality; and cultural adherence and continuity in identification with others from the child's ethnoracial group. 


\section{Case Example: Preventing Childhood Obesity by Increasing Psychological Resilience at School}

To illustrate the impact schools can have on resilience we can look at a specific problem like childhood obesity and the related problems of peer victimization, poor body image, low self-esteem and long-term threats to physical health that co-occur. Here, the connection between a child-specific problem and the social ecological factors that both increase risk and contribute to resilience is clear. On the risk side, obesity can be related to social class and the ability of caregivers to provide children with proper nutrition, as well as lifestyle decisions that are under the control of children's caregivers such as the frequency with which meals are eaten in front of a television (Gentile et al., 2009). Likewise, schools can influence the level of physical activity programmed into a child's curriculum, provide healthy alternatives for lunch and education regarding a healthy lifestyle and good nutrition (Crosnoe \& Muller, 2004). The challenge is to know which programs are likely to be the most effectively delivered by the child's school and which are better left to parents and caregivers and others in the child's community like health professionals.

Despite this gap in our knowledge, there is emerging evidence that schools can play a part in preventing obesity and, in the process, also prevent school disengagement and improve academic performance (Crooks, 1995; Mallick, 1983). Obesity and school engagement have long been understood as negatively related: obese youth are thought to underperform in school, be less engaged in school, be bullied by their classmates, form few meaningful relationships with other youth, and develop serious physical and mental health problems. Findings from contemporary studies that examine the relationship between obesity and school engagement have supported these beliefs (Crosnoe \& Meuller, 2004; Taras \& Potts-Datema, 2005). Florence, Asbridge, and Veugelers (2008), for example, have shown that youth with healthy diets are $30 \%$ less likely to receive failing grades in literacy assessments than youth with unhealthy diets. Likewise, a child's mental health may also be at risk if obese. Sjöberg, Nilisson, and Leppert (2005) have shown a statistically significant association between obesity in youth and depression, itself another factor that predicts school disengagement. Youth in Sjöberg et al.'s study exhibited high levels of shame and had become socially isolated from family and friends. Similarly, Lumeng et al. (2010) have shown a statistically significant association between obese youth and experiences of bullying leading to children's decisions to exclude themselves from dangerous school environments. Educators who have sought to implement obesity prevention programs in schools have shown moderate success helping obese children improve their physical health with the expectation that improvement in physical health will influence children's levels of school engagement positively (Oetzel, Scott, \& McGrath, 2009).

To illustrate, if we look at programs addressing obesity, resilience and school engagement, we see a pattern among educators who are leaning towards interventions that are multisystemic. School-based obesity prevention programs have shown a similar developmental pathway to that which has been shown previously in the literature on resilience. Obesity prevention programs have generally started out by implementing specialized curriculum in schools that focus on individual youth, teaching them about healthy eating and/or helping them to improve their self-esteem. Results from these programs have been mixed. As Smolak and Levine (2001) have shown, youth in their obesity prevention program exhibited higher levels of self-esteem and were less likely to engage in unhealthy weight loss strategies than youth in the control group. However, there were no significant differences in body weight between the two groups at follow-up. Similarly, results from Caballero et al.'s (2003) Pathways program did not show any variance in the obesity levels between youth in the intervention group and the control group. Pinhas-Hamiel, Singer, Pilpel, Fradkin, Modan and Reichman (2005) have argued that in order to provide more effective treatment to youth, obesity prevention programs have to expand outside the school to include involvement of the youth's family.

School-based obesity prevention programs that include a family component, however, have shown mixed results with youth. Blom-Hoffman, Wilcox, Dunn, Leff, and Power (2008) reported that their Five A Day program resulted in youth eating more fruits and vegetables than they did before participating in the program. Gentile et al. (2009)'s SWITCH program also saw an increase in youths' consumption of fruits and vegetables but no changes in body weight or physical activity. Participants in Story's et al. (2003) GEMS program also did not report any changes in body weight and there were no differences between youth in the intervention group and the control group.

Such disappointing results have moved obesity-prevention programs beyond the belief that youth alone can manage the barriers and challenges they face. As Alvaro et al. (2010) argue, obesity prevention programs must provide youth with quality service engagement and supports that are external to the youth. Currently, in schools across many western countries, health centres are being established with the intent of detecting, diagnosing and treating youths' physical and mental health problems in school. It is believed that these school based health centres will grant youth access to clinical services that they would not have access to otherwise (Clayton, Chin, 
Blackburn, \& Echeverria, 2010). Veugelers and Fitzgerald (2005) have shown the effectiveness of schools that promote comprehensive mental and physical health programs and initiatives. They found that grade 5 students in health promoting schools in Nova Scotia, Canada, were more physically active and had better diets than students from non-health-centric schools. In addition, Veugelers and Fitzgerald also found that students from health-promoting schools were $50 \%$ less likely to become overweight and $72 \%$ less likely to become obese than students from non-health promoting schools. While these school-based health centres are still in their nascent stages, early evaluations from Oetzel, Scott, and McGrath (2009) have shown that school health providers who are properly trained in psychosocial service delivery and shown how to engage with youth are more effective in treating youth obesity than before they received the specialized training. As the case example shows, addressing a complex problem like obesity and its threat to mental health, school engagement and academic performance can be done through the intentional application of principles rooted in an ecological understanding of resilience.

\section{Resilience and Schools: An Overview of Interventions}

As the examples above illustrate, there are many aspects of schooling that have the potential to enhance the resilience of children and youth in contextually and culturally meaningful ways (Hecht \& Raup-Krieger, 2006; National Crime Prevention Centre, 2009; Tebes et al., 2007). However, as Johnson and Howard (2007) showed in their longitudinal qualitative research with 55 young people in Australia, pathways to resilience are complex and respond to contexts like school in which child development takes place. While the individual exercises some degree of personal agency, contextual factors influence which protective factors are the most important and when. Related threats to academic achievement are known to be bullying (Pottinger \& Stair, 2009), the quality of relationships with teachers, principals, and staff (Morrison \& Allen, 2007; Sharkey, You, \& Schnoebelen, 2008), transitions between schools (McVey et al., 2003; Shortt, Hutchinson, Chapman, \& Toumbouro, 2007), the student's emotional and psychological wellbeing (Tebes et al., 2007; Wong et al., 2009), the child's gender, race, and class (Ollis \& Meldrum, 2008; National Crime Prevention Centre, 2009), and the availability of academic supports (Ager et al., 2011). Many of these factors have been addressed by school-based programs that remove threats to children's wellbeing while building the capacity of children to experience resilience.

For example, numerous studies have shown that a caring school community not only overrides the negative impact of learning challenges, but also helps to compensate for the disadvantages of living in communities where there are high concentrations of poverty and social marginalization, racial discrimination, and violence (Cassen, Feinstein, \& Graham, 2008; Minnard, 2002). Easy access to remedial education, universal curriculum that focuses on personal, social and health education (making schools one of the few places all children get the basic life skills they need to cope effectively with stress), personalised classroom learning and more equitable access to the funding schools need to offer a range of programs, make for schools that are effective with marginalized populations (Cassen et al., 2008). These programs, like others discussed in this review, show a pattern of intervention that focuses on changing the child's context rather than adapting the child to function in poorly resourced environments.

In particular, the most oft-studied factor is the way students, especially at-risk students, interact with their teachers and how that relationship fosters resilience. Resilience-promoting teachers have been shown in studies to do the following:

- They make themselves available and accessible to students;

- They engage students by actively listening to their concerns and worries;

- They take responsibility for actively teaching their students the basic reading, writing and numeracy skills needed for independent learning, even if their students have struggled in the past to master these skills;

- They have empathy with, and understanding of, their students' "tough" circumstances yet provide them with positive strategies to deal with adversity;

- They advocate for their students by mobilising existing support provisions that are available for "at risk" students'

- They actively use their power as adults and professionals to identify and oppose bullying and harassment at school; and finally,

- They remember the 'human touches' that promote pro-social bonding between teachers and students. (Johnson, 2008, p. 395)

\section{Findings: Resilience-Promoting Programs in Educational Settings}

Schools have become increasingly a place where educators and those concerned with prevention are 
implementing programs to give children the resources they need to cope with adversity (Johnson \& Howard, 2007). Among the interventions reviewed for this article, definitions of resilience vary. In some cases, resilience is understood as occurring when a child does not develop problem behaviours; in other instances resilience is realized through the development of a specific set of skills. As Minnard (2002) observed, there is not always a need for more resources to improve resilience; often the need is for resources to be used more effectively.

Combined, a thematic analysis of the design of the interventions and their evaluations show:

- There is support for the principle of differential impact, with children who are exposed to higher levels of adversity benefiting much more than lower risk children who participate in the same school-based programs. In some cases, a program only has a positive impact on children whose needs are high (Vazsonyi, Belliston, \& Flannery, 2004).

- Many of the programs that target higher risk-exposed children emphasize both non-academic and academic goals. The non-academic goals are considered helpful to engaging youth at school and increasing individual qualities that predict greater success in learning. These programs promote cultural activities, community-based initiatives that bolster self-esteem, connections with adults, prosocial behavior, lower drug use, decreased conduct disorder, and the prevention of delinquent behavior.

- When academic achievement is the explicit goal, it is usually achieved as a consequence of children's better engagement at school. For the more marginalized and disadvantaged children, attending school regularly has a positive influence on their ability to meet academic performance expectations.

- Programs with pre-school children, and those with children transitioning to middle school or high school, focus on improving school readiness, or remediation of learning problems such as poor literacy and numeracy skills. In these cases, program goals include enhancing academic performance and, as a consequence of school attendance and the learning that occurs in the classroom, giving children the resources they need to cope well with challenges that occur beyond their classrooms.

- Many programs emphasize the building of children's social capital, at home with supportive adults, at school with educators and with peers who behave in socially acceptable ways.

- International programs emphasize human rights education.

- Programs in Canada and the United States emphasize interpersonal skills, suppression of bullying, adapting the school and home environments to make it more likely children engage at school, and improve their academic performance.

- Gender issues are frequently considered when both national and international programs are implemented, with girls provided specialized help to access educational programs and participate fully in non-traditional areas of study. Boys are often treated differently with regard to engagement strategies or programs that target problem behaviors like gang involvement.

- Almost all of the programs used school-based samples, though many focused on factors that affect children outside of their schools such as the promotion of culture, better child-parent interaction, and the child's contribution to his or her community.

- While programs showed the potential to influence school engagement, academic performance, individual qualities like self-esteem, and improve children's interactions with their families and communities, programs were generally less effective addressing psychological problems like depression. It is unclear whether programs are ineffective because of their design or because problems like depression are complex and require interventions that are beyond a school's scope of practice. School-based programs did, however, prove effective at decreasing the risk factors for depression such as exposure to bullying, improving school climate and decreasing school disengagement.

- When the focus of school programming is on changing children's learning environments, programs tend to emphasize improved parent-teacher interactions, instigating non-punitive discipline strategies, and increasing expectations for academic performance of children who are socially or racially marginalized.

- Many interventions include changes to school-wide curricula, integrating learning modules that focus on the skills that make children resilient.

The list of programs and the factors they address is long. Across disciplines, there are, however, many similarities in their approaches. Significantly, service scans like that by Santor, Short and Ferguson (2009) of mental health and addictions programs for students in Canadian schools have shown that while there are many promising programs being implemented to address students' needs at school they tend to lack systematic and 
effective strategies or demonstrate sufficient fidelity to the models upon which they are based to guarantee their success. More well-considered programs, and efforts to build an evidence base for local initiatives that respond to local issues are needed.

\section{Discussion}

The 36 interventions identified for this review showed mixed results in terms of their effectiveness. Most did not include a cultural or contextual component. It is therefore difficult to say whether a program that was offered was actually the best one for the population being studied, or whether the selection of a particular intervention reflects the bias of educators, researchers and the program's funders. It is also unclear whether there may have been other more effective programs that were not considered, or whether cultural differences could have been better accounted for by a program developed locally.

There were multiple programs that were aimed at helping students adopt "positive" behaviours and attitudes (see Farrell, Meyer, \& White, 2001; Hallam, 2009; Nelson, Martella, \& Marchand-Martella, 2002; Shek \& Ma, 2012; Vazsonyi, Belliston, \& Flannery, 2004). Such an approach to building resilience can be controversial. By predefining what is a prosocial behaviour, educators are at risk of imposing their values onto the children who participate in programming. Research suggests that in contexts of greater adversity, perceived negative behaviours may help children and youth maintain a sense of wellbeing (Ungar, 2006). Furthermore, differences in mental health, socio-economic status, parental and familial support, and so forth, create barriers to school engagement that are too complex to be resolved by a single intervention. As Shortt, Hutchinson, Chapman, and Toumbouro (2007) showed in their work on alcohol abuse prevention, it is important to be sensitive to the meaning a particular behaviour has in different contexts and cultures. Their school-based resilience program was supposed to prevent young people from abusing alcohol but was ineffective in part because the youth's parents held liberal views on alcohol use and would allow their children to consume alcohol in their homes. In failing to take into consideration the context in which underage drinking occurs, researchers may overlook possible solutions (for example, addressing alcohol abuse among teens through interventions with their parents). Our review highlights similar patterns. The best school-based interventions appear to be collaborative, multisystemic and culturally and contextually relevant, responding to what children themselves say they need.

\subsection{A Note about Research and Program Evaluation}

We note that many programs did show some positive impact on resilience-related factors for students. However, the scope of their assessment measures tended to be narrow. Most of these school-based outcome evaluations of programs predefined acceptable behaviour as school engagement and academic performance, even though much of the research suggests that schools serve many other psychological and social functions for their students. This lack of a contextually sensitive approach to research and programming has meant that outcomes associated with resilience may not be measured, and socially unacceptable behaviours like truancy that children use to protect themselves in threatening, resource poor environments may be overlooked as potentially useful (though maladaptive) coping strategies. While we would not, of course, design a program that promotes truancy, we understand that in challenging contexts students who perceive few prosocial options to achieve psychological wellbeing avoid academic failure and maintain physical safety by disengaging from school (Dei, Massuca, McIsaac, \& Zine, 1997).

\section{Conclusion}

To the extent that we shape school, community, and family environments, the more likely we are to engage young people in learning and enhance overall resilience. Programs with an empirical evidence base and those that report practice-based evidence both show common design elements. Good programs interrupt patterns of behaviour that are likely to lead to academic failure and disengagement from school by changing a student's social ecology. With respect to efforts to nurture and sustain resilience, our scoping review of programs suggests that earlier is always better, but it is never too late to begin to make a difference.

\section{References}

Aboriginal Affairs and Northern Development. (2012). First Nation Student Success Program - Success Stories. Ottawa, ON: Government of Canada.

Ager, A., Akesson, B., Stark, L., Flouri, E., Okot, B., McCollister, F., \& Boothby, N. (2011). The impact of the school-based Psychosocial Structured Activities (PSSA) program on conflict-affected children in northern Uganda. Journal of Child Psychology and Psychiatry. http://dx.doi.org/10.1111/j.1469-7610.2011.02407.x 
Alvaro, C., Jackson, L. A., Kirk, S., McHugh, T. L., Hughes, J., Chircop, A., \& Lyons, R. F. (2010). Moving governmental policies beyond a focus on individual lifestyle: Some insights from complexity and critical theories. Health Promotion International.

Bierman, K., Domitrovich, C., Nix, R., Gest, S., Welsh, J., Greenberg, M., ... \& Domitrovich, C. E. (2008). Promoting academic and social-emotional school readiness: The Head Start REDI Program. Child Development, 79(6), 1802-1817. http://dx.doi.org/10.1111/j.1467-8624.2008.01227.x

Blom-Hoffman, J., Wilcox, K., Dunn, L., Leff, S., \& Power, T. (2008). Family involvement in School-Based Health Promotion: Bringing nutrition information home. School Psychology Review, 37(4), 567-577.

Caballero, B., Clay, T., Davis, S. M., Ethelbah, B., Rock, B. H., Lohman, T., ... \& Stevens, J. (2003). Pathways: A school-based, randomized controlled trial for the prevention of obesity in American Indian schoolchildren. The American Journal of Clinical Nutrition, 78(5), 1030-1038.

Cassen, R., Feinstein, L., \& Graham, P. (2008). Educational outcomes: Adversity and resilience. Social Policy \& Society, 8(1), 73-85. http://dx.doi.org/10.1017/S1474746408004600

Clayton, S., Chin, T., Blackburn, S., \& Echeverria, C. (2010). Different setting, different care: Integrating prevention and clinical care in school-based health centers. American Journal of Public Health, 100(9), 1592-1596. http://dx.doi.org/10.2105/AJPH.2009.186668

Covell, K. (2010). School engagement and rights respecting schools. Cambridge Journal of Education, 4(1), 39-51. http://dx.doi.org/10.1080/03057640903567021

Crosnoe, R., \& Muller, C. (2004). Body mass index, academic achievement, and school context: Examining the educational experiences of adolescents at risk of obesity. Journal of Health and Social Behavior, 45(4), 393-407. http://dx.doi.org/10.1177/002214650404500403

Crooks, D. (1995). American children at risk: Poverty and its consequences for children's health, growth, and school achievement. American Journal of Physical Anthropology, 38(S2), 57-86. http://dx.doi.org/10.1002/ajpa.1330380605

Cunningham, E. G., Brandon, C. M., \& Frydenberg, E. (2002). Enhancing coping resources in early adolescence through a school-based program teaching optimistic thinking skills. Anxiety, Stress \& Coping: An International Journal, 15(4), 369-381. http://dx.doi.org/10.1080/1061580021000056528

D’Angelo, F., \& Zemanick, R. (2009). Twilight Academy: An alternative education program that works. Preventing School Failure, 53(4), 211-218. http://dx.doi.org/10.3200/PSFL.53.4.211-218

Dei, G., Massuca, J., McIsaac, E., \& Zine, J. (1997). Reconstructing “drop-out”: A critical ethnography of the dynamics of Black students' disengagement from school. Toronto: University of Toronto Press.

Dotterer, A. M., McHale, S. M., \& Crouter, A. C. (2009). Sociocultural factors and school engagement among African American youth: The roles of racial discrimination, racial socialization, and ethnic identity. Applied Developmental Science, 13(2), 61-73. http://dx.doi.org/10.1080/10888690902801442

Elias, M., Gara, M., Schuyler, T., Branden-Muller, L., \& Sayette, M. (1991). The promotion of social competence: Longitudinal study of a preventive school-based program. American Journal of Orthopsychiatry, 61(3), 409-417. http://dx.doi.org/10.1037/h0079277

Farrell, A., Meyer, A., \& White, K. (2001). Evaluation of Responding in Peaceful and Positive Ways (RIPP): A school-based prevention program for reducing violence among urban adolescents. Journal of Clinical Child Psychology, 30(4), 451-463. http://dx.doi.org/10.1207/S15374424JCCP3004_02

Florence, M. D., Asbridge, M., \& Veugelers, P. J. (2008). Diet Quality and Academic Performance. Journal of School Health, 78(4), 209-215. http://dx.doi.org/10.1111/j.1746-1561.2008.00288.x

France, A., Bottrell, D., \& Armstrong, D. (2012). A political ecology of youth and crime. London, UK: Palgrave MacMillan. http://dx.doi.org/10.1057/9781137291486

Frey, K., Bobbitt, N. S., Van Schoiack, E. L., \& Hirschsteinb, M. (2005). Effects of a school-based social-emotional competence program: Linking children's goals, attributions, and behavior. Applied Developmental Psychology, 26(2), 171-200. http://dx.doi.org/10.1016/j.appdev.2004.12.002

Gentile D. A., Welk, G., Eisenmann, J. C., Reimer, R. A., Walsh, D. A., Russell, D. W., .. \& Fritz, K. (2009). Evaluation of a multiple ecological level child obesity prevention program: Switch what you Do, View, and Chew. BMC Medicine, 7, 1-12. http://dx.doi.org/10.1186/1741-7015-7-49 
Gillham, J., Reivich, R., Freres, D., Chaplin, T., Shatte, A., Samuels, B., ... \& Seligman, M. E. P. (2007). School-based prevention of depressive symptoms: A randomized controlled study of the effectiveness and specificity of the Penn Resiliency Program. Journal of Consulting and Clinical Psychology, 75(1), 9-19. http://dx.doi.org/10.1037/0022-006X.75.1.9

González, M., Penelo, E., Gutiérrez, T., \& Raich, R. (2011). Disordered eating prevention programme in schools: A 30-month follow-up. European Eating Disorders Review, 19(4), 349-356. http://dx.doi.org/10.1002/erv.1102

Hallam, S. (2009). An evaluation of the Social and Emotional Aspects of Learning (SEAL) programme: Promoting positive behaviour, effective learning and wellbeing in primary school children. Oxford Review of Education, 35(3), 313-330. http://dx.doi.org/10.1080/03054980902934597

Harnet, P., \& Dadds, M. (2004). Training school personnel to implement a universal school-based prevention of depression program under real-world conditions. Journal of School Psychology, 42(5), 343-357. http://dx.doi.org/10.1016/j.jsp.2004.06.004

Hecht, M., \& Raup-Krieger, J. (2006). The principle of cultural grounding in school-based substance abuse prevention: The Drug Resistance Strategies Project. Journal of Language and Social Psychology, 25(3), 301-319. http://dx.doi.org/10.1177/0261927X06289476

Holen, S., Waaktaar, T., Lervåg, A., \& Ystgaard, M. (2012). The effectiveness of a universal school-based programme on coping and mental health: A randomised, controlled study of Zippy's Friends. Educational Psychology: An International Journal of Experimental Educational Psychology, 32(5), 657-677. http://dx.doi.org/10.1080/01443410.2012.686152

Hobfoll, S. E. (2011). Conservation of resource caravans and engaged settings. Journal of Occupational and Organizational Psychology, 84, 116-122. http://dx.doi.org/10.1111/j.2044-8325.2010.02016.x

Johnson, B. (2008). Teacher-student relationships which promote resilience at school: A micro-level analysis of students' views. British Journal of Guidance \& Counselling, 36, 385-398. http://dx.doi.org/10.1080/03069880802364528

Johnson, B., \& Howard, S. (2007). Causal chain effects and turning points in young people's lives: A resilience perspective. Journal of Student Wellbeing, 1(2), 1-15.

Lumeng, J. C., Forrest, P., Appugliese, D. P., Kaciroti, N., Corwyn, R. F., \& Bradley, R. H. (2010). Weight status as a predictor of being bullied in third through sixth grades. Pediatrics, 125(6), 1301-1307. http://dx.doi.org/10.1542/peds.2009-0774

Mallick, M. J. (1983). Health hazards of obesity and weight control in children: A review of the literature. American Journal of Public Health, 73(1), 78-82. http://dx.doi.org/10.2105/AJPH.73.1.78

Mallin, B., Walker, J. R., \& Levin, B. (2013). Mental health promotion in the schools: Supporting resilience in children and youth. In S. Prince-Embury, \& D. H. Saklofske (Eds.), Resilience in Children, Adolescents, and Adults (pp. 91-112). New York: Springer. http://dx.doi.org/10.1007/978-1-4614-4939-3_7

Martin, A. J., \& Marsh, H. W. (2008). Academic buoyancy: Towards an understanding of students' everyday

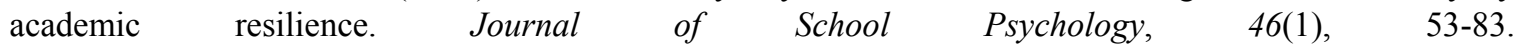
http://dx.doi.org/10.1016/j.jsp.2007.01.002

Martin, A. J., \& Marsh, H. W. (2009). Academic resilience and academic buoyancy: Multidimensional and hierarchical conceptual framing of causes, correlates and cognate constructs. Oxford Review of Education, 35(3), 353-370. http://dx.doi.org/10.1080/03054980902934639

McVey, G., Lieberman, M., Voorberg, N., Wardrope, D., Blackmore, E., \& Tweed, S. (2003). Replication of a peer support program designed to prevent disordered eating: Is a life skills approach sufficient for all middle school students? Eating Disorders, 11(3), 187-195. http://dx.doi.org/10.1080/10640260390218639

Minnard, C. V. (2002). A strong building: Foundation of protective factors in school. Children \& Schools, 24(4), 233-246. http://dx.doi.org/10.1093/cs/24.4.233

Morrison, G., \& Allen, M. (2007). Promoting student resilience in school contexts. Theory Into Practice, 46(2), 162-69. http://dx.doi.org/10.1080/00405840701233172

National Crime Prevention Centre. (2009). The Aboriginal EMPATHIC Program. Public Safety Canada. 
Nelson, J., Martella, R., \& Marchand-Martella, N. (2002). Maximizing student learning: The effects of a comprehensive school-based program for preventing problem behaviors. Journal of Emotional Behaviors and Disorders, 10(3), 136-148. http://dx.doi.org/10.1177/10634266020100030201

Oetzel, K., Scott, A., \& McGrath, J. (2009). School-Based Health Centers and Obesity Prevention: Changing $\begin{array}{llll}\text { Practice Through Quality Improvement. Pediatrics, 123(sup), S267-S271. } & \text {. }\end{array}$ http://dx.doi.org/10.1542/peds.2008-2780D

Ollis, D., \& Meldrum, K. (2008). "Be yourself and have a ball": Using a school and community based health education model to build young women's resilience and connectedness. In T. Association (Ed.), AARE 2008: International Education Research Conference. Changing Climates: Education for Sustainable Futures (pp. 1-16). Coldstream, Australia: Association.

Pathways to Education. (2011). Pathways to Education Canada Results Summary. Retrieved April 23, 2013, from http://www.Pathwaystoeducation.ca

Pattison, C., \& Lynd, S. R. (2001). The prevention of depressive symptoms in children: The immediate and long-term outcomes of a school based program. Behaviour Change, 18(2), 92-102. http://dx.doi.org/10.1375/bech.18.2.92

Pinhas-Hamiel, O., Singer, S., Pilpel, N., Fradkin, A., Modan, D., \& Reichman, B. (2005). Health-related quality of life among children and adolescents: Associations with obesity. International Journal of Obesity, 30, 267-372. http://dx.doi.org/10.1038/sj.ijo.0803107

Pottinger, A. M., \& Stair, A. G. (2009). Bullying of students by teachers and peers and its effect on the psychological well-being of students in Jamaican schools. Journal of School Violence, 8(4), 312-327. http://dx.doi.org/10.1080/15388220903130155

Public Safety Canada. (2011). Gwich'in Outdoor Classroom. Retrieved October 1, 2012, from http://www.publicsafety.gc.ca/res/cp/ev/gw-eng.aspx

Richman, J. M., \& Fraser, M. W. (2001). The context of youth violence: Resilience, risk, and protection. Westport, CT: Praeger Publishers.

Santor, D., Short, K., \& Ferguson, B. (2009). Taking mental health to school: A policy-oriented paper on school-based mental health for Ontario. The Provincial Centre of Excellence for Child and Youth Mental Health at CHEO. Retrieved November 14, 2012, from http://www.excellenceforchildandyouth.ca/sites/default/files/position_sbmh.pdf

Sharkey, J., You, S., \& Schnoebelen, K. (2008). Relations among school assets, individual resilience, and student engagement for youth grouped by level of family functioning. Psychology in the Schools, 45(5), 402-418. http://dx.doi.org/10.1002/pits.20305

Sheffield, J., Spence, S., Rapee, R., Kowalenko, N., Wignall, A., Davis, A., \& McLoone, J. (2006). Evaluation of universal, indicated, and combined cognitive-behavioral approaches to the prevention of depression among adolescents. Journal of Consulting and Clinical Psychology, 74(1), 66-79. http://dx.doi.org/10.1037/0022-006X.74.1.66

Shek, D., \& Ma, C. (2012). Impact of the Project P.A.T.H.S. in the junior secondary school years: Objective outcome evaluation based on eight waves of longitudinal data. The Scientific World Journal.

Shortt, A. L., Hutchinson, D. M., Chapman, R., \& Toumbouro, J. W. (2007). Family, school, peer and individual influences on early adolescent alcohol use: First-year impact of the Resilient Families programme. Drug and Alcohol Review, 26(6), 625-634. http://dx.doi.org/10.1080/09595230701613817

Sjöberg, R. L., Nilsson, K. W., \& Leppert, J. (2005). Obesity, shame, and depression in school-aged children: A population-based study. Pediatrics, 116(3), e389-e392. http://dx.doi.org/10.1542/peds.2005-0170

Smolak, L., \& Levine, M. (2001). A two-year follow-up of a primary prevention program for negative body image and unhealthy weight regulation. Eating Disorders, 9(4), 313-325. http://dx.doi.org/10.1080/106402601753454886

Story, M., Sherwood, N., Himes, J., Davis, M., Jacobs, D., Cartwright, Y., ... \& Rochon, J. (2003). An after school obesity prevention program for African American girls: The Minnesota GEMS pilot study. Ethnicity \& Disease, 13, 54-64.

Taras, H., \& Potts-Datema, W. (2005). Obesity and Student Performance at School. Journal of School Health, 75(8), 291-295. 
Tebes, J., Feinn, R., Vanderploeg, J., Chinman, M., Shepard, J., Brabham, T., .. \& Connell, C. M. (2007). Impact of a positive youth development program in urban after-school settings on the prevention of adolescent substance use. Journal of Adolescent Health, 41(3), 239-247. http://dx.doi.org/10.1016/j.jadohealth.2007.02.016

Ungar, M. (2006). Nurturing Hidden Resilience in At-Risk Youth in Different Cultures. Journal of Canadian Academic Child Adolescent Psychiatry, 15(2), 53-58.

Ungar, M. (2011). The social ecology of resilience: Addressing contextual and cultural ambiguity of a nascent $\begin{array}{lllll}\text { construct. American Journal of } & \text { Orthopsychiatry, } & 81(1), & 1-17 .\end{array}$ http://dx.doi.org/10.1111/j.1939-0025.2010.01067.x

Ungar, M., Brown, M., Liebenberg, L., Othman, R., Kwong, W. M., Armstrong, M., \& Gilgun, J. (2007). Unique pathways to resilience across cultures. Adolescence, 42(166), 287-310.

Ungar, M., \& Liebenberg, L. (2013). Ethnocultural factors, resilience, and school engagement. School Psychology International, 34(5), 514-526. http://dx.doi.org/10.1177/0143034312472761

Ungar, M., Liebenberg, L., Armstrong, M., Dudding, P., \& van de Vijver, F. J. R. (2012). Patterns of service use, individual and contextual risk factors, and resilience among adolescents using multiple psychosocial services. Child Abuse \& Neglect.

Vazsonyi, A., Belliston, L., \& Flannery, D. (2004). Evaluation of a school-based, universal violence prevention program: Low-, medium-, and high-risk children. Youth Violence and Juvenile Justice, 2(2), 185-206. http://dx.doi.org/10.1177/1541204003262224

Veugelers, P. J., \& Fitzgerald, A. L. (2005). Effectiveness of school programs in preventing childhood obesity: A multilevel comparison. Journal Information, 95(3), 432-435.

Walker, H., Kavanagh, K., Stiller, B., Golly, A., Severson, H., \& Feil, E. (1998). First step to success: An early intervention approach for preventing school antisocial behavior. Journal of Emotional and Behavioral Disorders, 6(2), 66-80. http://dx.doi.org/10.1177/106342669800600201

Webster-Stratton, C., Reid, M., \& Stoolmiller, M. (2008). Preventing conduct problems and improving school readiness: Evaluation of the Incredible Years Teacher and Child Training Programs in high-risk schools. Journal of Child Psychology and Psychiatry, 49(5), 471-488. http://dx.doi.org/10.1111/j.1469-7610.2007.01861.x

Wong, M., Sun, J., Lee, A., Stewart, D., Cheng, F., Kan, W., \& Ho, M. (2009). The impact of a newly designed resilience-enhancing programme on parent- and teacher-perceived resilience environment among health promoting schools in Hong Kong. Journal of Epidemiology \& Community Health, 63, 209-214. http://dx.doi.org/10.1136/jech.2008.074260

\section{Appendix}

Table 1. Selected sample of school programs that enhance factors associated with resilience

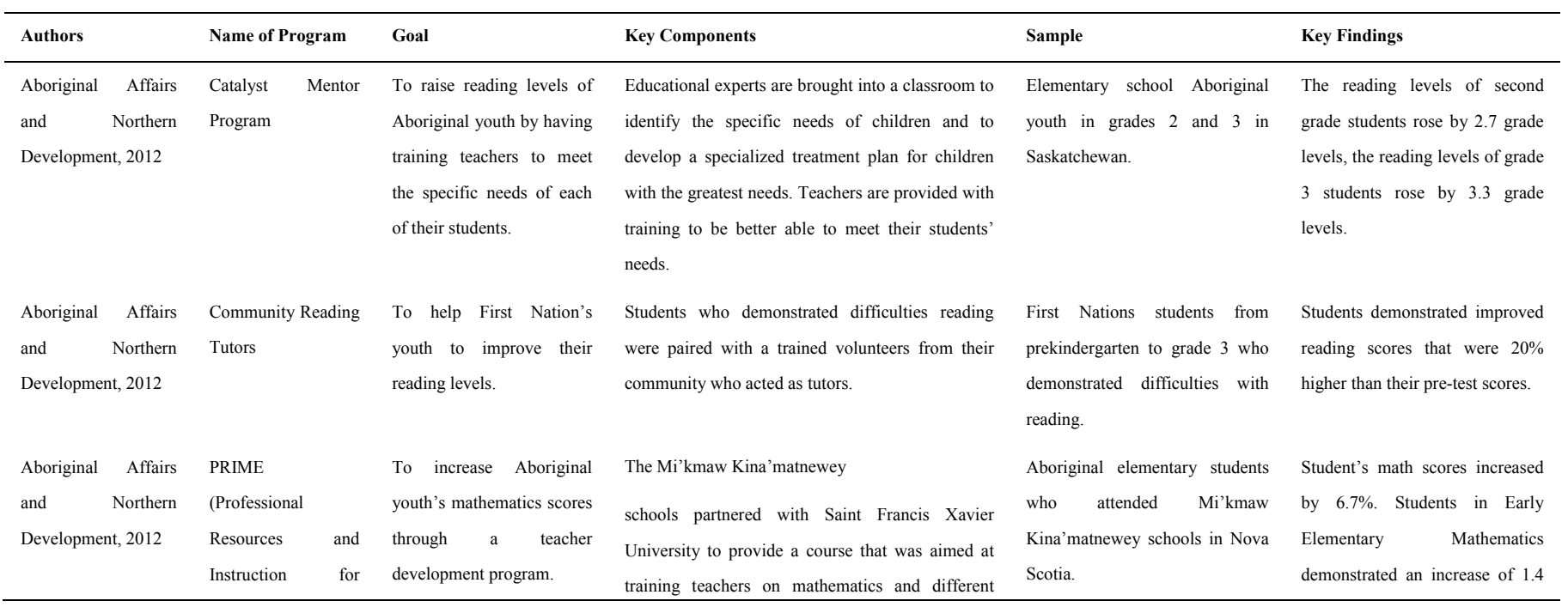




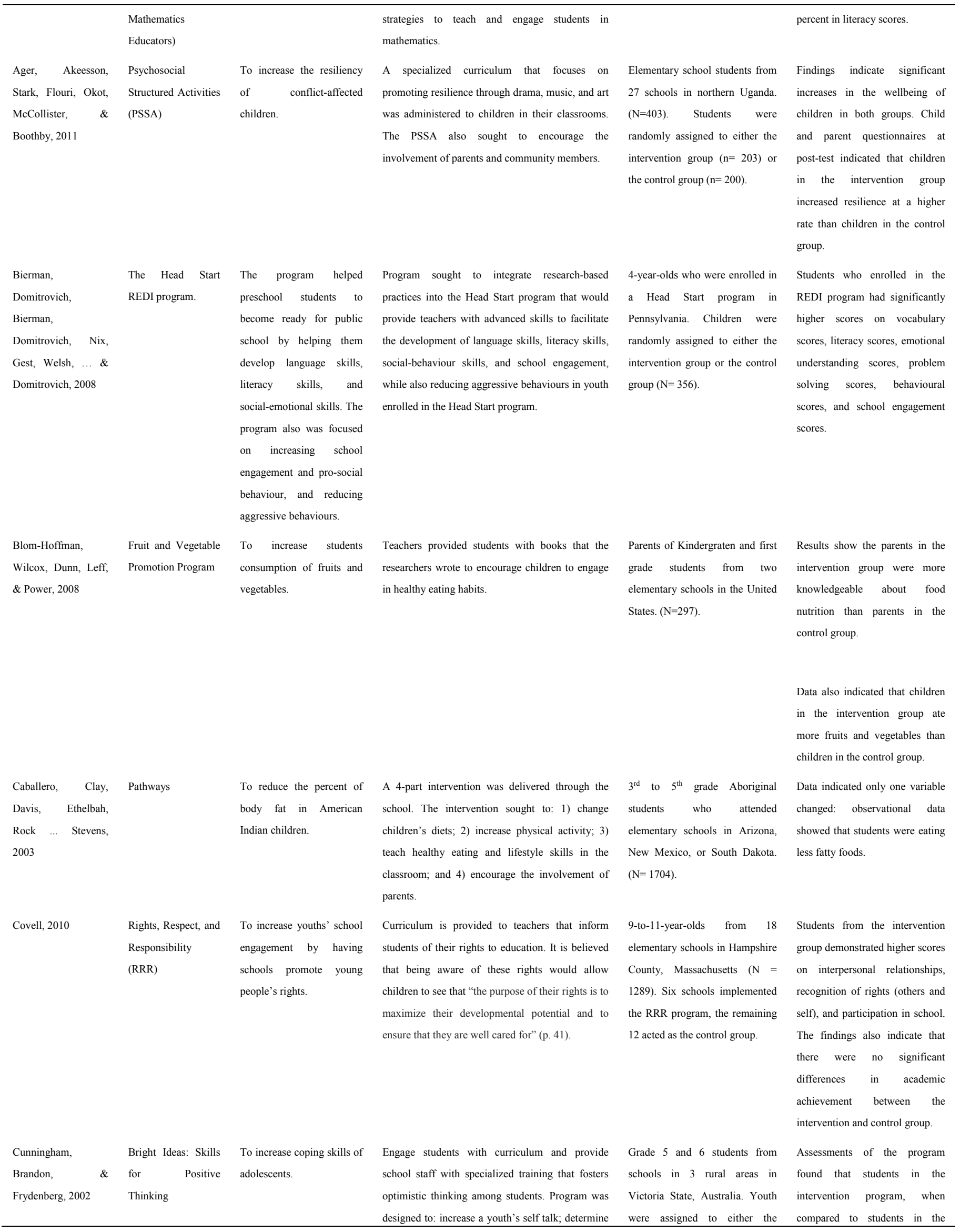


the accuracy of their self talk; develop alternative solutions or attributions; and prevent harmful and destructive thinking.

intervention group or the control group. $(\mathrm{N}=295)$

\begin{abstract}
D'Angelo \& Twilight Academy

Zemanick, 2009

To help youth (typically defined as at-risk or high-risk youth) who had trouble adapting to traditional classroom settings graduate from high school.
\end{abstract}

Elias, Gara, Schuylet, Branden-Muller, \& Sayette, 1991

Social Decision
To build protective factors within children who are transitioning into Junior High school, making them less susceptible to risk factors. Making and Social Problem Solving (SDS-SPS)
The program offered at-risk and high-risk youth smaller class sizes, more one-on-one attention from teachers, supportive teachers, and the integration of real life problems into teaching materials.
Introduced curriculum that taught youth decision-making and problem-solving skills that will help them avoid engaging in anti-social activities.
High school students who had low attendance records, disruptive behaviours, and/or were in jeopardy of not graduating from high school were nominated to the program by teachers and school staff. Participants were in Grades 9-12 from a school in Southeastern Pennsylvania. $(\mathrm{N}=60)$.

Students from elementary schools who are transitioning into junior high school. Students were randomly assigned to a control group and an intervention group.
Farrell, Meyer, \& Responding in To reduce youths' violent White, 2001

\section{behaviour.}

Peaceful

Positive

(RIPP)
Program introduced a specialized curriculum that was taught by prevention specialists, that teaches youth to utilize nonviolent behaviours, positive communication, achievement of pro-social goals, and healthy problem-solving technique.
Grade 6 students who are not receiving educational assistance services. Students were from 3 junior high schools in Richmond, Virginia. Students were randomly assigned to either the intervention group $(\mathrm{N}=305)$ or the control group $(\mathrm{N}=321)$ control group, demonstrated significant improvements in positive and efficient coping strategies. This was shown by intervention students scoring lower on depressive symptoms and unhealthy coping strategies (i.e., excessive worrying, ignoring problems) than the control group.

Findings show that of the 12 students who were eligible to graduate, 11 did so on time while the other students graduated after completing summer school.

Findings from the 2-year follow-up evaluation showed youth in the intervention group had improved coping skills and had less disruptive behavioural outbursts. Findings at the 6-year follow up showed that students in the intervention group behaved better than the control group. Boys in the control group had higher rates of alcohol use, violence, and psychological problems than intervention group. Similarly, girls in the control group showed higher rates of vandalism and cigarette use.

Program assessments found that youth in the RIPP program demonstrated less violent behaviour and received fewer suspensions from school than youth in the control group.

Post-tests demonstrated that RIPP participants engaged in less violent behaviour and used peer mediation more frequently than control group youth when trying to resolve disagreements.

Boys enrolled in RIPP maintained low suspension rates at the 12-month follow-up. Girls 
in the RIPP program did not demonstrate the same outcome.

\begin{tabular}{|c|c|c|c|}
\hline $\begin{array}{lr}\text { Frey, } & \text { Bobbitt, } \\
\text { Edstromb, } & \&\end{array}$ & Second Step & $\begin{array}{l}\text { To decrease aggression and } \\
\text { to increase social }\end{array}$ & $\begin{array}{l}\text { Engage students with curriculum, that was aimed } \\
\text { at fostering emotional, behavioural, and cognitive }\end{array}$ \\
\hline Hirschsteinb, 2005 & & $\begin{array}{l}\text { responsibility } \\
\text { empathetic and } \\
\text { students. }\end{array}$ & $\begin{array}{l}\text { skills, decreasing students aggressive outbursts, } \\
\text { and encouraging pro-social goal setting and values. } \\
\text { School staff administered the curriculum to } \\
\text { students. Staff were provided with specialized } \\
\text { training from researchers before beginning the } \\
\text { program. }\end{array}$ \\
\hline
\end{tabular}

Gillham, Reivich, Penn Resiliency To prevent youth from Freres, Chaplin, Program (PRP) developing depressive Shatte, ... Seligman, 2007

González Gutierrez, \& Raich, 2011

\section{Hallam, 2009}

The PRP is a cognitive-behavioural intervention that is administered to youth in their classrooms. Youth are taught about their feelings, how they think about feelings, and effective problem-solving skills.

Implement curriculum in the classroom that is designed to promote positive behaviours, self-awareness, effective management of feelings, improve motivation and empathy, and increase social skills.
Disordered Eating Prevention Program and to discourage students from adopting stereotypical ideals about healthy body types.

Social and To develop and increase Emotional Aspects of Learning (SEAL) social, emotional, and behavioural skills in elementary school students.
Findings demonstrate that the program had more of an impact on high-risk youth than any other group.

Grade 5 and 6 students from 2 elementary schools in Washington state $\quad(\mathrm{N}=1,253)$. Students were randomly assigned to either the control group or the intervention group.

Results from the evaluation found students in the control group demonstrated a reduction in aggressive behaviour and cooperated more than youth from the control group.

Students in the intervention group required less adult supervision than students in the control group.

Students in the intervention group identified more pro-social goals and actively pursued them.

Students in the intervention group recognized the rights of others more than students in the control group.

697 youth from 3 junior high schools from a metropolitan area in the United States. Youth were randomly assigned to one of 3 groups: the PRP group; the control group; or the Penn Enhancement Program (PEP) group (The PEP is specialized program that helps youth cope with the stressors associated with depression).

443 elementary students from Spain. Students were randomly assigned to the control group, the media literacy group, or the media literacy and nutritional awareness group.

Elementary students from 78 schools in the United Kingdom $(\mathrm{N}=5474)$.

$87 \%$ of teachers and $96 \%$ of non-teaching staff said that the program had a positive impact on children's emotional wellbeing 
manage their emotions

$\begin{array}{lll}\begin{array}{l}\text { Harnett \& Dadds, } \\ 2004\end{array} & \begin{array}{l}\text { Resourceful } \\ \text { Adolescent Program } \\ \text { (RAP) }\end{array} & \begin{array}{l}\text { To reduce depressive } \\ \text { symptoms in youth. }\end{array} \\ & & \\ & & \\ \text { Hecht \& } & \begin{array}{l}\text { Keepin' it REAL } \\ \text { (Refuse, Explain, }\end{array} & \text { To prevent adolescent drug } \\ \text { Raup-Krieger, 2006 } & \text { Avoid, Leave) } & \end{array}$

Holen, Waaktaar, Zippy’s Friends

Lervåg, \& Ystgaard,

2012
McVey, Lieberman, Voorberg, Wardrope, Blackmore, \& Tweed, 2003
National Crime Prevention Centre of Canada, 2009
Girl Talk

$\&$

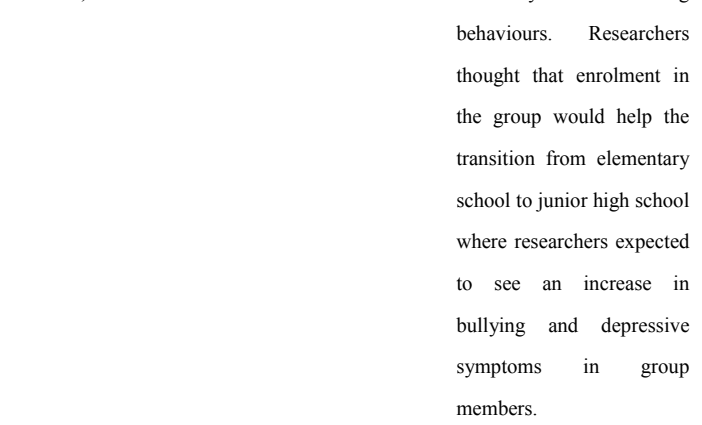

To improve adolescent girls' self-esteem, body esteem, and to reduce unhealthy dieting behaviours. Researchers thought that enrolment in the group would help the transition from elementary school to junior high school where researchers expected members.

EMPATHTIC To improve the emotional Program (Emotional awareness and impulse Maturity control of Aboriginal Problem-Solving \& children living in Eskasoni,
Teachers were trained and provided with a specialized curriculum that was aimed at reducing the depressive symptoms in their students.

A culture-based curriculum was designed to provide youth with different ways to decline invitations from others to use drugs and alcohol. The curriculum is also based on youths' perceptions and experiences of pressure to use drugs and alcohol, helping youth to develop effective strategies to decline offers to use substances.

Teachers were provided with a specialized curriculum that is designed to help strengthen

children's coping strategies.
Grade 9 and 10 students. Youth were randomly assigned to an intervention group or a control group.

Grade Seven students from 35 of 45 junior high schools in Phoenix, Arizona. Students were randomly assigned into 4 groups that provided the following curricula: control group (no curriculum);

Mexican-American-based

curriculum; Black/White-based curriculum; and multicultural curriculum.

Grade 2 students from 35 schools in Norway. $(\mathrm{N}=1483)$. Students were randomly assigned to either the intervention group or the control group.
$48 \%$ of teachers and $74 \%$ of non-teaching staff said the program reduced bullying.

There were no significant differences in depression scores between students in the intervention group and the control group.

There was significantly less drug and alcohol use by students in the culture-based curricula than the control group. The multicultural curriculum was the most effective.

Findings show that girls and underprivileged children showed increases in effective coping strategies. Boys who were enrolled in the program appeared to be less affected by mental health problems.
The program implemented a peer support program where students provided support to their fellow program members regarding their body image, self-esteem, and to prevent unhealthy dieting activities.

A specialized curriculum was implemented in Eskasoni's elementary and junior high schools. The curriculum was age-appropriate and culturally specific. In addition, a program representative went
Adolescent girls in Grades 7 and 8 from 16 elementary schools in a Canadian suburb $(\mathrm{N}=282) .196$ girls were in the control group and 86 were in the intervention group.
Students in the intervention group demonstrated a higher incidence of eating disorders than the control group. No other significant findings were found.
Elementary and junior high school students in Eskasoni, Nova Scotia.
Students and teachers reported that students were better able to cope with their feelings and developed better problem-solving 


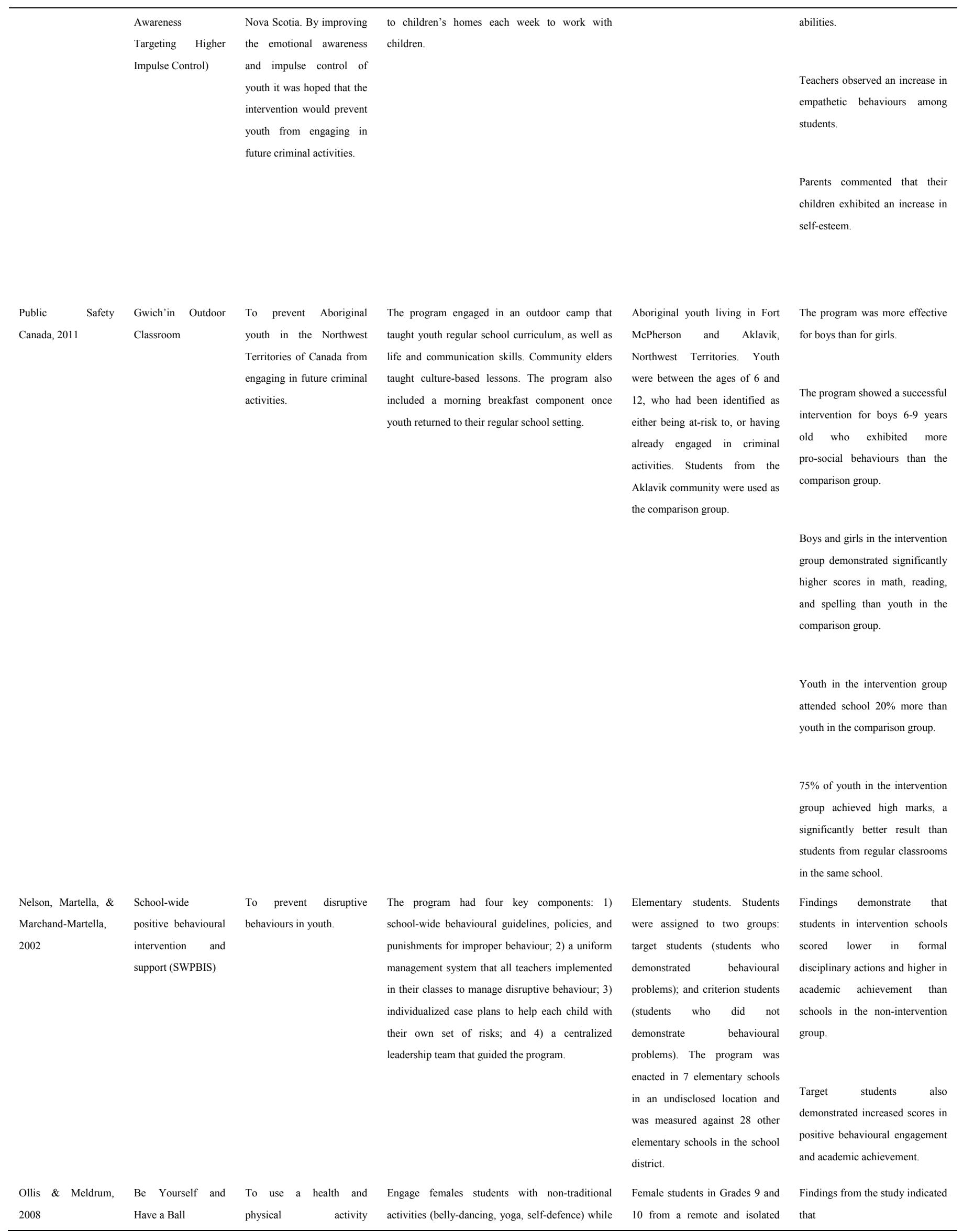


intervention to build resilience, connectedness to the community, school, and peers among female

students. simultaneously provide them with an understanding of health issues relative to their gender and age. community in Australia. $(\mathrm{N}=25)$

(n)

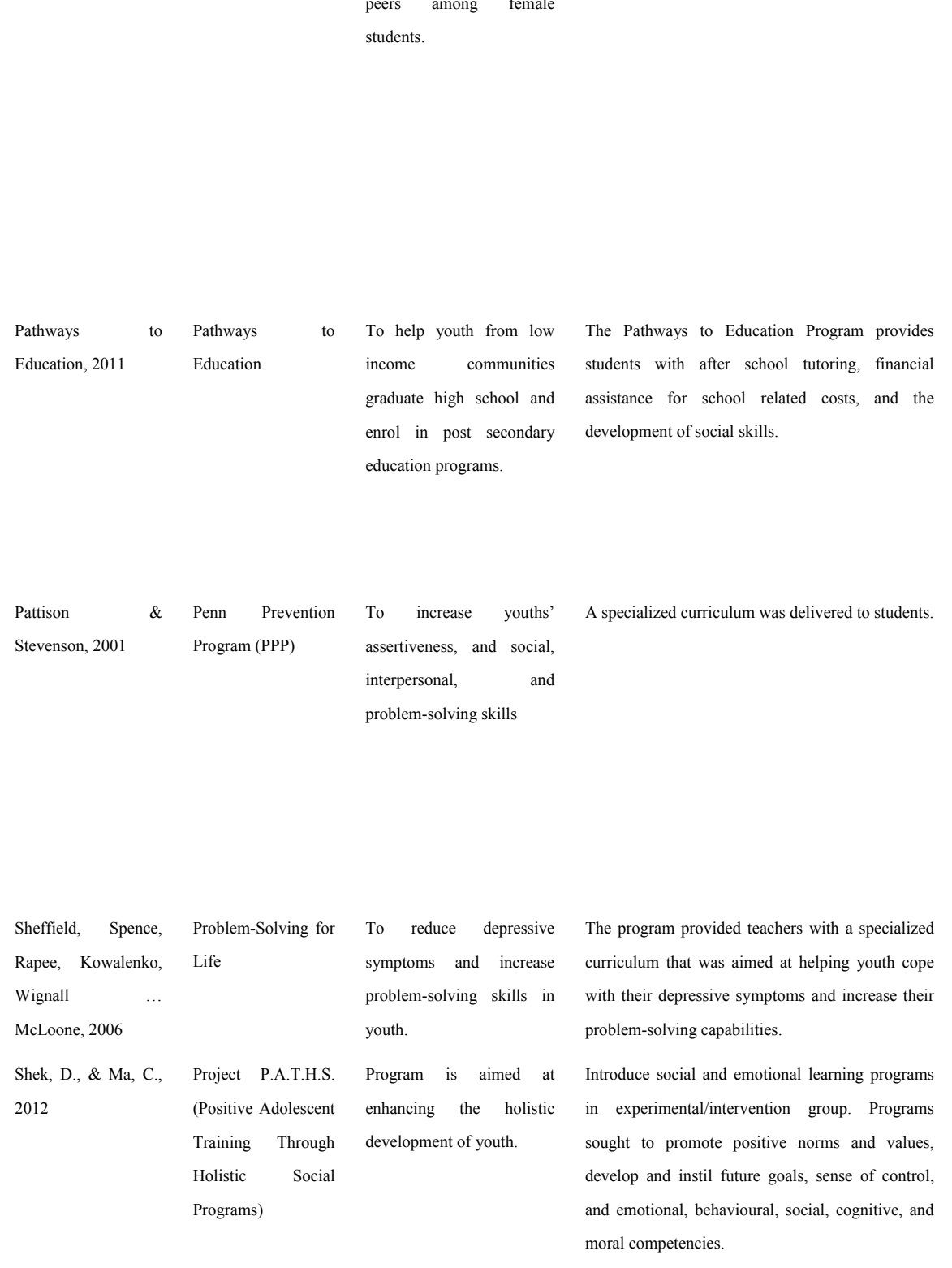

Sheffield, Spence, Problem-Solving for To reduce depressive

Rapee, Kowalenko, Life

Wignall ..

McLoone, 2006

Shek, D., \& Ma, C. (Positive Adolescent

Training Through

Programs)

Shortt, Hutchison, Resilient Families

Chapman,
High school students from 12 low income communities across Canada who are at risk of dropping out of school.

Grade 5 and Six students living in rural communities in Australia. $(\mathrm{N}=63)$. Students were randomly assigned to either the control group, PPP (problem solving components then cognitive components), or Reverse PPP (Cognitive components followed by problem-solving components). Grade Nine students. Students were randomly assigned to a control group and an intervention group.

Youth enrolled in Grade One in schools in Hong Kong at the beginning of the study were measured annually for 8 years. Students in the experimental/intervention group $(\mathrm{N}=2,662)$; Youth in the control group $(\mathrm{N}=3,272)$. It is not clear how the students were assigned to either group.
A positive impact on their relationships with their peers was found.

Students engaged in bullying behaviours less often.

Students enrolled in the program have doubled their graduation rates from before the intervention. There was a $70 \%$ reduction in dropouts, $85 \%$ increase in participation, and a $300 \%$ increase in enrolment in postsecondary institutions.

There were no significant differences found between the three groups.

There were no significant findings between the control group and the intervention group.

Findings from the longitudinal data indicate a significant difference in positive youth development between the experimental group and the control group. Youth in the experimental group demonstrated better development than the youth in the control group. These findings were most noticeable in behavioural, moral, and cognitive behavioural competencies.

Youth who perceived the program as being beneficial also did significantly better than youth who did not perceive there to be any benefits to the program.

Findings did not demonstrate a difference in rates of alcohol use 


\begin{tabular}{|c|c|c|c|c|c|}
\hline Toumbouro, 2007 & & $\begin{array}{l}\text { transitioning from } \\
\text { elementary school to junior } \\
\text { high school. }\end{array}$ & $\begin{array}{l}\text { The goal of which is to: increasing knowledge and } \\
\text { skills such as emotional awareness, peer resistance } \\
\text { skills, and problem solving skills to help youth } \\
\text { avoid early alcohol use/abuse; present parents with } \\
\text { knowledge and specialized training to help their } \\
\text { children avoid using/abusing alcohol; and forge a } \\
\text { more involved relationship between parents and } \\
\text { their child(ern)'s school. }\end{array}$ & $\begin{array}{l}\text { Australia. ( } \mathrm{N}=2128) \text {. Students } \\
\text { were randomly assigned to either } \\
\text { the intervention or control group. } \\
\text { There was no indication as to } \\
\text { how many of the students were } \\
\text { assigned to either groups. }\end{array}$ & $\begin{array}{l}\text { between the intervention and } \\
\text { control groups. The data showed } \\
\text { that alcohol use went from } 33 \% \\
\text { in Grade } 7 \text { to } 47 \% \text { in Grade } 8 . \\
\text { The data also showed that } \\
\text { students in the intervention group } \\
\text { achieved more in school than } \\
\text { youth in the control group. }\end{array}$ \\
\hline $\begin{array}{l}\text { Smolak \& Levine, } \\
2001\end{array}$ & $\begin{array}{l}\text { Eating Smart, Eating } \\
\text { for Me }\end{array}$ & $\begin{array}{l}\text { To improve students' } \\
\text { nutrition, increase exercise } \\
\text { and body esteem, and to } \\
\text { discourage unhealthy } \\
\text { dieting strategies. }\end{array}$ & $\begin{array}{l}\text { Students were engaged with } 10,1 \text { hour lessons } \\
\text { during school. }\end{array}$ & $\begin{array}{l}\text { Students were originally 9-11 } \\
\text { when the program was first } \\
\text { implemented, the } 2 \text { year follow } \\
\text { up was conducted with 11-13 } \\
\text { year olds. ( } \mathrm{N}=509 \text { ). Students } \\
\text { were randomly assigned to either } \\
\text { the intervention or control group. }\end{array}$ & $\begin{array}{l}\text { Students in the intervention } \\
\text { group were shown to be more } \\
\text { knowledgeable about nutrition, } \\
\text { had higher body esteem, and } \\
\text { were less likely to engage in } \\
\text { unhealthy dieting strategies. }\end{array}$ \\
\hline $\begin{array}{l}\text { Story, } \quad \begin{array}{r}\text { Sherwood, } \\
\text { Himes, }\end{array} \\
\text { Jacobs, }\end{array}$ & $\begin{array}{l}\text { Girls health } \\
\text { Enrichment } \\
\text { Multi-site Studies } \\
\text { (GEMS) }\end{array}$ & $\begin{array}{l}\text { To prevent female African } \\
\text { American youth from } \\
\text { becoming obese. }\end{array}$ & $\begin{array}{l}\text { Students took part in an after school program that } \\
\text { focused on increasing physical activity and } \\
\text { promoting healthy eating practices. The after } \\
\text { school program also required the participation of } \\
\text { parents. }\end{array}$ & $\begin{array}{l}\text { African American females aged } \\
\text { 8-10 years old from elementary } \\
\text { schools in Minnesota and their } \\
\text { parents. (N=54). Participants } \\
\text { were randomly assigned to either } \\
\text { the control or intervention group. }\end{array}$ & $\begin{array}{l}\text { Findings showed no significant } \\
\text { differences between the control } \\
\text { and intervention groups. }\end{array}$ \\
\hline $\begin{array}{l}\text { Tebes, Feinn, } \\
\text { Vanderploeg, } \\
\text { Chinman, } \\
\text { Shepard...\& Connell, } \\
2007\end{array}$ & $\begin{array}{l}\text { Positive Youth } \\
\text { Development } \\
\text { Collaborative } \\
\text { (PYDC) }\end{array}$ & $\begin{array}{l}\text { To prevent adolescent } \\
\text { substance abuse and to } \\
\text { promote feelings of } \\
\text { wellbeing. }\end{array}$ & $\begin{array}{l}\text { The program introduced an after-school curriculum } \\
\text { that sought to instil healthy coping techniques, } \\
\text { prevention skills, problem solving methods, and a } \\
\text { sense of cultural heritage and civic responsibility in } \\
\text { youth. Curriculum included information sessions, } \\
\text { cultural and heritage sessions, and field trips to } \\
\text { surrounding community institutions and services. }\end{array}$ & $\begin{array}{l}\text { Junior and high school students } \\
\text { from two cities in North-eastern } \\
\text { United States. Students were } \\
\text { placed in either the intervention } \\
\text { group }(\mathrm{N}=149) \text { or the control } \\
\text { group }(\mathrm{N}=155) \text {. }\end{array}$ & $\begin{array}{l}\text { Assessments at the end of the } \\
\text { program found a significant } \\
\text { difference in how youth in the } \\
\text { control group and youth in the } \\
\text { intervention group viewed } \\
\text { substance use. Youth in the } \\
\text { intervention group viewed } \\
\text { substance abuse as being } \\
\text { dangerous more often than youth } \\
\text { in the control group. } \\
\text { One year follow-up interviews } \\
\text { found that youth in the } \\
\text { intervention group demonstrated } \\
\text { significantly lower increases in } \\
\text { alcohol and drug use than youth } \\
\text { in the control group. }\end{array}$ \\
\hline $\begin{array}{l}\text { Vazsonyi, Belliston, } \\
\text { \& Flannery, } 2004\end{array}$ & Peacebuilders & $\begin{array}{l}\text { School-based violence } \\
\text { prevention program aimed } \\
\text { at low, medium, and } \\
\text { high-risk youth who are at } \\
\text { risk of engaging in violent } \\
\text { behaviour. }\end{array}$ & $\begin{array}{l}\text { The program implemented a specialized } \\
\text { curriculum that rewarded positive social behaviour, } \\
\text { encouraged youth to avoid encouraging anti-social } \\
\text { behaviour, and to help youth better manage their } \\
\text { violent behaviours. The curriculum was } \\
\text { implemented by school staff. }\end{array}$ & $\begin{array}{l}\text { Elementary students between } \\
\text { grades primary and } 5 \text { from } 9 \\
\text { schools in Tucson, AZ. Youth } \\
\text { were selected because they lived } \\
\text { in neighbourhoods with high } \\
\text { rates of crime, violence, and } \\
\text { juvenile arrests. } \\
(\mathrm{N}=2,380) \text {. }\end{array}$ & $\begin{array}{l}\text { Results from the study show: } \\
\text { There were decreases in } \\
\text { aggressive behaviours for both } \\
\text { high-risk boys and girls. } \\
\text { High-risk boys and girls both } \\
\text { demonstrated increases in social } \\
\text { competence in school. } \\
\text { No changes were found for } \\
\text { medium-risk children. }\end{array}$ \\
\hline
\end{tabular}




$\begin{array}{lrl}\text { Walker, Kavanagh, } & \text { First Step to Success } & \text { To increase future school } \\ \text { Stiller, } & \text { Golly, } & \text { engagement } \\ \text { Severson, \& Feil, } & \text { kindergarten students who } \\ 1998 & & \text { have been identified as } \\ & \text { at-risk of developing } \\ & \text { anti-social behaviours. }\end{array}$

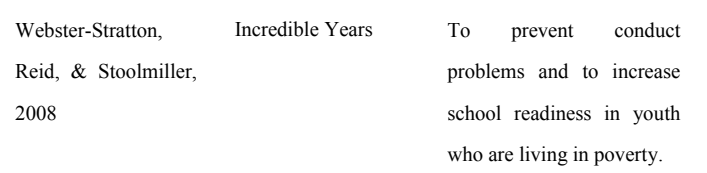

Wong, Sun, Lee, Stewart, Cheng, Kan, \& Ho, 2009

\section{Hong Kong Healthy}

School Award (HKHSA)
To strengthen students psychological wellbeing and resilience.
Use intervention programs both at school and at home to improve youth's adjustment to, and performance in school.

Teachers are trained in a specialized curriculum (the Dinosaur School Curriculum) that aims to: improve teachers' classroom management strategies in relation to needs of children with conduct disorders; prevent or reduce youth from developing conduct problems/disorders; and increasing parental involvement in education and behavioural management.

Parents and teachers were provided with specialized training to help promote resilience and psychological wellbeing in students.

Low-risk children saw slight increases in violent behaviours.

Kindergarten students who have been identified as developing aggressive and/or oppositional behaviours. Students were randomly assigned to either an intervention group or a control group. $(\mathrm{N}=46)$.

Kindergarten and Grade One students who were enrolled in a Head Start program in the Seattle, Washington area. Students were randomly assigned to either the intervention group or the control group $(\mathrm{N}=1,768)$.

4918 parents and 602 teachers who taught youth between the ages of 8 and 12 years old. Participants were selected from a low socio-economic region in China.

Parents and teachers were randomly assigned to either the intervention group or the control group.
Findings showed slight reductions in antisocial behaviour and a slight increase in school engagement.

Findings show that youth in the intervention group had less conduct problems, had more social competencies and self-regulation, and more parental involvement than youth in the control group.

There were no significant differences found among youth while enrolled in the intervention and control elementary schools. Students in the intervention group who attended junior high showed a significantly higher score in psychological wellbeing and resilience than students in the control group.

\section{Copyrights}

Copyright for this article is retained by the author(s), with first publication rights granted to the journal.

This is an open-access article distributed under the terms and conditions of the Creative Commons Attribution license (http://creativecommons.org/licenses/by/3.0/). 